\title{
Ora (direis) ouvir maravilhas...
}

\author{
André Luis Mitidieri-Pereira*
}

Resumo: Este trabalho parte das inferências de João David Pinto Correia sobre os relatos de viagem e expansão, segundo o qual o olhar realça o sujeito em seu poder de observar as terras a que chega. Ao olhar "ingênuo", seguir-se-ia um outro, sob os impactos do deslumbramento, do horror e da fantasia. Tendo em mira As viagens, de Marco Polo, discutem-se as visões daquele professor português a respeito de narradores viajantes, considerando-se as formas culturais populares e as narrações da oralidade no período em que foi escrito e começou a circular o "livro das maravilhas" do mercador veneziano.

Palavras-chave: Alteridade; Colonialismo; Literatura de Viagens; Marco Polo.

\begin{abstract}
This paper aims to examine João David Pinto Correia's theoretical inferences about the narratives of travel and expansion of some European empires. According to the Portuguese professor, the act of looking escalates the subject's observational power regarding those lands he reaches. This "naive look" would be followed by another one, which suffers the impacts of fascination, horror and fantasy. The present analysis is then concentrated on Marco Polo's As viagens [The travels of Marco Polo], discussing Correia's points of view concerning travelling narrators. It also takes into consideration some forms of popular culture and oral narratives, which were common during the period when the Venetian tradesman's "book of wonders" was written and started being spread over the world.
\end{abstract}

Keywords: Colonialism; Marco Polo; Otherness; Travelling Literature.

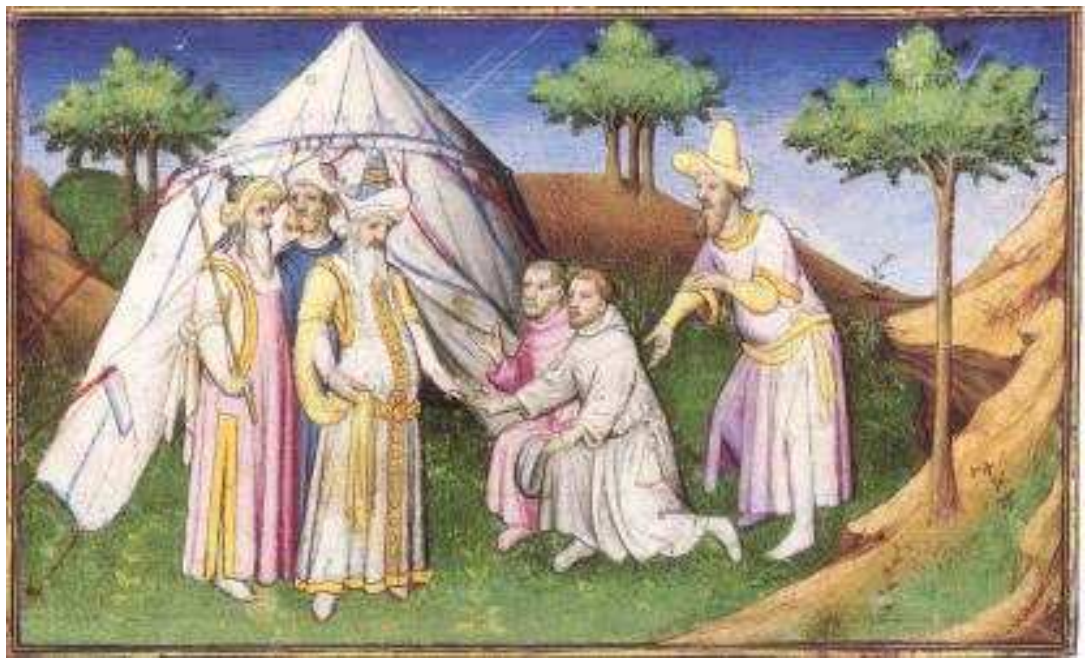

Figura 1: Kublai Khan com Nicolo e Matteo Polo

Fonte: www.marcopolo.mooldoo.com, 2006.

\footnotetext{
* André Luis Mitidieri-Pereira é doutorando em Letras, na área de Teoria da Literatura, pela PUCRS.
} 
Em um dos artigos que integra a coletânea de Fernando Cristóvão, intitulada $O$ olhar do viajante (2003), João David Pinto Correia (CRISTÓVÃO, 2003, p. 11-33) enfoca os relatos de viagem e expansão, afirmando que, neles, a ação dos olhos faz-se imperativa. Olhar corresponde ao espaço, realçando o sujeito em seu poder de observar terras descobertas, invadidas ou visitadas. Substantivado, tal verbo se redimensiona; lança-se ao estrangeiro, ao estranho, ao Outro.

Aos olhares tidos por "ingênuos", puros ou simples, seguir-se-ia uma visão imediatamente posterior — a do "olhar com olhos de ver" —, fortemente impactada pelo deslumbramento, pelo horror e pela fantasia. Tendo em mira As viagens, de Marco Polo", serão discutidos os pontos de vista desse professor português em relação aos narradores viajantes.

Não se deixa de considerar as formas culturais populares, bem como as narrações da oralidade, no período em que foi escrito e começou a circular o "livro das maravilhas" do famoso cidadão de Veneza. Para tanto, lembra-se que a antiga coordenação da alma, do olhar e da mão é típica do trabalhador artesanal; sempre a encontramos "onde quer que a arte de narrar seja praticada." (BENJAMIN, 1994, p. 221).

Inicialmente, a visão do mercador nada tem de límpida face aos grandiosos cenários e diversos episódios com os quais se defronta entre os anos de 1272 e 1295. Ele vem se contaminando, desde que parte à Ásia, até relatar suas longas jornadas a Rustico de Pisa, um escritor de novelas de cavalaria, na prisão de Gênova, no ano de 1298. As lembranças às quais se lança o senhor Polo, não totalmente recuperadas, como na verdade nunca são, trafegam dos ouvidos à pena do companheiro de cárcere, encarregado de narrar em seu nome.

Como vem repetindo a sabedoria popular, em "olhos que a terra há de comer", o olhar serve para dar credibilidade às histórias do comerciante, o qual as relata e diz que por si mesmo as viu. Entre as coisas que o veneziano pôde ver, olhou e das quais ouviu, ou diz ter ouvido falar, encontra-se a breve retomada da incursão do pai e do tio ao Oriente, iniciada em 1250. Nicolai Polo mais o irmão, Matteo, ocupam um espaço textual que se estende desde as primeiras páginas até o quarto capítulo do livro de Marco, também denominado "Milhão"2.

Já no prólogo dessa obra, o narrador tenta passar a impressão de que os viandantes olham somente por olhar, à medida que cavalgam até chegarem à presença de Barca Cã, o

\footnotetext{
${ }^{1}$ POLO Marco. As viagens. Traduzido por Ivone Castilho Benedetti. São Paulo: Martins Fontes, 1997. Tradução de Il libro di Marco Polo deto Il Milione. Todas as citações são retiradas dessa edição.

${ }^{2}$ Os Polo valiam-se do designativo Melione para se distinguirem de outros venezianos com o mesmo nome. Como os contemporâneos de Marco acreditam que ele exagera em seus relatos, passam a chamá-lo e, depois a seu livro, de Il Milione (O Milhão). Nota do tradutor. Cf. POLO, 1997, p. 05.
} 
senhor da Horda de Ouro ou dos tártaros do Poente. Na presença de Kublai Khan, rei de todos os tártaros, contudo, a dupla se põe aos seus serviços, no sentido de pedir ao papa que envie seis sábios, para mostrarem "aos que adoram ídolos e a quantas outras leis de lá que a lei deles era totalmente diferente e que toda ela era obra do diabo, e que soubessem demonstrar como argumentos que a lei cristã era melhor" (POLO, 1997, p. 06-07).

Nessa missão, os mercadores aportam a São João de Acre, principal porta de passagem para a Terra Santa, em abril do ano 1272. Devendo esperar até que um novo papa fosse eleito, dirigem-se aos domínios venezianos, onde teriam ficado até 1274. Como a eleição do pontífice não se concretiza, decidem retornar à Ásia, em expedição que será acompanhada pelo jovem Marco, contando 15 anos de idade e órfão de mãe.

Os três cavaleiros levam três anos para ir de Veneza à residência de verão do Grão Cã, e suas experiências de viajantes desenvolvem-se até um período posterior à chegada na Mongólia. Os entraves e sucessos com que o trio se depara são brevemente narrados em terceira pessoa, pelo mesmo novelista encarcerado, desde o quinto capítulo ao de número XIII:

Marco, filho do senhor Niccolò, no pouco tempo que ficou na corte aprendeu os costumes tártaros, suas línguas e suas letras, e tornou-se homem sábio e de valor sem igual. E quando o grão cã viu nesse jovem tanta agudeza, enviou-o como embaixador a uma cidade, aonde custou seis meses para chegar. O jovem voltou bem, e sabiamente contou a embaixada e outras notícias sobre as coisas que lhes perguntou porquanto vira outros embaixadores volver de terras outras sem saberem dar notícias dessas terras senão as da embaixada; ele considerava-os néscios, e dizia gostar mais de conhecer os diversos costumes da terra que de conhecer aquilo pelo que os havia mandado (POLO, 1997, p. 11).

Tratando de aprender as coisas para repeti-las ao Grão Cã, e feito embaixador, o jovem Polo teria viajado pelo império tártaro durante vinte e sete anos. Essa informação, entretanto, é contestada pela nota de número 30: "Na realidade dezessete, visto que Marco chegou a Clemenefu no verão de 1274" (POLO, 1997, p. 207). A envelhecer e a sedentarizar-se, o mercador se encaixa nas duas formas por excelência de narradores - o marujo aventureiro e o camponês sedentário - a recobrarem vida nas comunidades de trabalho do sistema corporativo que vigorou entre o fim das Idades Médias e a Era Moderna (BENJAMIN, 1994, p. 198-206).

Anteriormente, um dos registros memorialísticos do aventureiro Milione é repassado oralmente ao narrador. Não mais o jovem que era, na época de suas aventuras, o comerciante dá conta de que seus dois familiares, pai e tio, agora lembrados, haviam chegado à província de Acre em 1272. A informação, entretanto, vem a ser retificada por uma nota explicativa: “Trata-se de 1269; Clemente IV morreu em novembro de 1268” (POLO, 1997, p. 206). 
Tal e qual a memória do homem maduro, o texto por ele protagonizado se contamina; nem só pelo esquecimento, como também pela vigência da retórica. Para a renovação dessa arte da "elocução", da "disposição" e do "ornato", revela-se importante, na obra, a interação da lógica com o raciocínio gramatical. Essa combinação gerou a "gramática especulativa" no século XIII, decorrente da redescoberta das Categorias e do De Interpretatione de Aristóteles no Ocidente.

Ao fim da mesma centúria, e pelo mesmo tempo em que o livro do riquíssimo veneziano estava sendo escrito, floresceu a Ars Dictaminis, parte da retórica que trata das regras para composição de cartas e outros documentos em prosa, cujos ensinamentos parecem evidenciados logo a seguir:

Digo-vos ainda que foi pela confiança nesses três embaixadores, porque o grão cã neles confiava, que lhes confiou a rainha kachin e a filha do rei dos manji, para que a conduzissem a Argun, senhor de todo o Levante. E assim foi feito. E essas rainhas consideravam-nos como pais e assim lhes obedeciam. E quando eles partiram para regressar à sua terra, essas rainhas choraram com grande dor. Despedindo-se os três embaixadores de Acatu, foram para Trebizonda, depois para Constantinopla, Negroponte e finalmente Veneza; e isso aconteceu em 1295. Agora que vos contei o prólogo do livro do senhor Marco Polo, aqui se começa a discorrer sobre as províncias e terras por onde andou (POLO, 1997, p. 13-14).

É desse modo que aquele recluso contador de histórias, ainda se valendo da terceira pessoa para relatar as aventuras de Marco, passa a se intercalar às primeiras pessoas do singular ou do plural, entre as quais se divide a voz do veneziano. O senhor Polo também narra suas viagens a partir do capítulo XIV. Seus primeiros relatos ao Grão Cã, recontados ao escriba, não demonstram deslumbramento nem horror.

Ademais, o olhar não é limpo, pois assinalado pela racionalidade aristotélica, que impregnou a doutrina de Tomás de Aquino nos anos de 1200, e pode ser atestada no seguinte fragmento: "Ali há muitas cidades e castelos, uma abundância de todas as coisas, havendo aves e casa em grande quantidade. Ali costumava haver homens valentes: agora são todos ruins, tendo-lhes restado um dote: são grandes bebedores" (POLO, 1997, p. 14).

A descrição direta referenda a visão tomística de mundo, a partir da qual quase não havia lugar para alegorias e imagens poéticas. Esse mesmo ponto de vista será verificado na conquista aos Manji, no sul da China. Por um lado, o deslumbramento, o horror e a fantasia, por parte de quem chega, são sumariamente afastados da narrativa. Por outro lado, o rei, cujos domínios seriam invadidos, era adepto da astrologia, tendo previsto a derrota de seu povo por um homem de quem diziam possuir cem olhos. O monarca foge e deixa a mulher na defesa, enquanto os adversários aproximam-se de seus territórios.

Chefiados por "Baiam Cem Olhos", encarregado de tal mister pelo Grão Cã, os combatentes se deparam com a rendição de todas as cidades inimigas. Os defensores 
esmorecem porque a rainha havia se lembrado daquela profecia. Se o olhar dos povos dominados pode ser ingênuo, o dos invasores não se apresenta como tal, visto que as hordas já haviam partido com a informação de que aqueles povos não eram afeitos a armas. Ainda que no mundo inteiro não houvesse reino como o dos Manji, Marco Polo não se deslumbra com sua grandeza, nem os soldados tártaros se horrorizam com as águas muito fundas ao seu redor.

Do ponto de vista dos conquistadores, o episódio não é fantasioso, pois tanto se verifica a rendição dos seus conquistados, por motivos místicos, quanto a chegada de Baiam aos campos de batalha, "com muita gente e com muitos navios, que carregavam homens a pé e a cavalo" (POLO, 1997, p. 118). O olhar transforma-se em passivo "mal-olhado" sobre a cultura belicamente inferior, e a invasão igualmente se explica por uma entredita inferioridade religiosa: "quando alguém quer fazer uma viagem ou alguma coisa vai ter com seus astrólogos, nos quais têm grande fé" (POLO, 1997, p. 129).

Os tempos das histórias narradas testemunharam o realce cristão à extrema misericórdia da virgem Maria e ao sacrifício dos mártires. No entanto, os espaços narrativos do "livro das maravilhas" não deixam de dialogar com a fé islâmica, lembrada por intermédio da frase: "Se Maomé não vai à montanha, a montanha vai a Maomé". Tal provérbio se estabelece no texto, a modo de uma ruína de antigas narrativas, em que "a moral da história abraça um acontecimento, como a hera abraça um muro" (BENJAMIN, 1994, p. 221).

Comunicando-se com os mitos de Édipo, da estátua de sal e da magia paralisante da Esfinge, os quais se vinculam ao olhar, a imagem da montanha maometana transparece na seguinte passagem:

Quando o bispo teve aquela visão, de que pelo sapateiro a montanha deveria mover-se, mandou reunir todos os cristãos e contou-lhes sua visão. Então o bispo pediu ao sapateiro que suplicasse a Deus que movesse a montanha; e ele respondeu que não era homem suficiente para isso. Quando o prazo se esgotou, pela manhã, todos os cristãos foram à igreja e mandaram cantar missa, implorando a Deus que os ajudasse; depois tiraram a cruz e foram para o vale em frente àquela montanha [...] E o califa chegou com muitos sarracenos armados para matar todos os cristãos, achando que a montanha não se moveria. E como os cristãos continuassem em oração ajoelhados diante da cruz e suplicando esse feito a Deus, a montanha começou a desabar e a mover-se. Os sarracenos, vendo aquilo, muito se admiraram, e o califa converteu-se com muitos sarracenos (POLO, 1997, p. 20-21).

O mito do paraíso, cujo reencontro vem sendo prometido por várias religiões e seitas, reaparece em Mílice, onde antigamente costumava ficar o velho da montanha. Esse mandara erguer um legítimo jardim das delícias. Os sarracenos do lugar acreditavam na ilusão paradisíaca. Naquele vale, entre duas montanhas, estaria "o maior e o mais belo jardim do mundo: ali havia todos os frutos e os mais belos palácios, todos pintados com ouro, animais e 
pássaros. Havia vários canais: por uns chegava água, por outros mel e por outros, vinho" (POLO, 1997, p. 29).

Quando o ancião queria matar alguém, ordenava que dessem beberagens soníferas a alguns jovens lá postos a viver e que os levassem para o seu palácio. Ao acordarem, os moços se admiravam, ficando tristes por se verem fora do paraíso. Iam logo conversar com o velho, dizendo-lhe que tinham grande vontade de voltar ao local que haviam abandonado. Os rapazes matavam para poder voltar ao jardim, construído com intuitos de homologar o desconhecido, e segundo anteriores propostas de representação, dadas por narrativas orais.

Aqui sim é válida a interferência da fantasia na visão do Outro, pois o paraíso do ancião se associa àquele que era descrito por Maomé. O olhar dos jovens mostra-se cobiçoso, porém, como os rudes marinheiros de Camões, os moços julgam "as cousas só pela aparência", contando-as por certas e verdadeiras. Já o olhar do velho revela-se malicioso; por "puro engelho e ciência"3, pois ele fabrica os fatos falsos ou mal-entendidos. Não narra para escapar à morte, mas para matar, sem que suje de sangue as suas mãos.

O local fantasioso, e que se conserva e deposita a memória do Islã, é apresentado como um inimigo a ser combatido, nesses tempos de transposição do fundo apocalíptico oriental e ocidental ao fundamento messiânico judaico. A recompensa no além é oferecida pelo cristianismo e recuperada pelo poder secular eclesiástico, ao passo que o povo permanece majoritariamente milenarista, na espera da volta do Messias e de um paraíso terrestre (FRANCO JR, 1986).

A narração justifica, dessa maneira, o ataque ao jardim, comandado por Alau, senhor dos tártaros do Levante. Tal fato, cuja ocorrência histórica é autenticada pela nota explicativa de número 83, não chega a imprimir traços de horror ao conteúdo narrado e se orienta em função de diferenças religiosas. Por sua vez, os indícios da crueldade do idoso da montanha não se configuram como visadas ingênuas, pois decorrem da sua heresia. Vale lembrar que os sonhos da Europa convergiam "para este objetivo: um Grande Cã dos mongóis, católico, apostólico e romano, faria soar o dobre de finados dos povos de Maomé para a glória eterna do cristianismo e do Ocidente reunido" (YERASIMOS, 1999, p. 11).

O horror é mostrado, embora hipoteticamente, por meio da "grande cobra e a grande serpente que, de tão grande, deveriam maravilhar a todos" (POLO, 1997, p. 104). Mais tarde, horror e medo são referendados: "coisa horrível de se ver: digo-vos que de fato há algumas

\footnotetext{
3 "Os casos vi, que os rudos marinheiros, / Que tem por mestra a longa experiência, / Contam por certos sempre e verdadeiros / Julgando as cousas só pola aparência, / E que os que tem juízos mais inteiros, / Que só por puro engenho e por ciência / Vem do mundo os segredos escondidos, Julgam por falsos ou mal entendidos". Cf. CAMÕES, 1982, p. 135.
} 
com dez passadas de comprimento, dez palmos de grossura; estas são as maiores" (POLO, loc. cit.). A fantasia vem a ser inserida pelo narrador de maneira paradoxal; ele se vale do conhecido para descrever o desconhecido, tentando tornar a realidade compreensível. Por outro lado, provoca terror, ao tomar o crocodilo pelo monstro (a grande cobra), cujos "pés têm garras como as do leão; o focinho é muito grande, e a cara é maior do que um pão grande; a boca é tal que poderia engolir um homem inteiro" (POLO, loc. cit).

Nas províncias de Caraja e Mie, onde encontra selvas e bosques, elefantes, unicórnios e outros bichos diversos, o maravilhado veneziano submete-se "ao despertar de mecanismos intertextuais, os quais possibilitam a projeção de uma construção fantasiosa, feita talvez de fragmentos retidos de leituras ou derivas imaginárias sobre o efectivamente visto" (CORREIA, 2003, p. 32). Da mesma maneira que cataloga o rinoceronte como unicórnio e depois retifica a definição legendária, o relator recorre aos cinocéfalos, presentes na Epistola Alexandri ad Aristotelem ou em De Rebus in Oriente Mirabilibus, para dar cabeças de cão a todos os habitantes de Agama.

Assim também procede com o lendário grifo dos gregos, do qual se utiliza para denominar o Ruck, animal mítico, para cuja configuração confluem várias tradições orientais. Se ainda caberia certo questionamento sobre a credibilidade suscitada pela informação: "tudo é verdade porque eu, Marco, vi-o depois com meus olhos" (POLO, 1997, p. 126), o narrador entremeia a real Quinsai, no reino dos Manji, à sua estabelecida significação como "cidade do céu", "a mais nobre e melhor cidade do mundo". Sem detalhar tantas nobrezas e qualidades, o ex-relator de Kublai Khan estaria por ventura autenticando a existência de um lugar por onde não teria andado, precisando para isso empenhar os próprios globos oculares?

Todavia, sempre quando possível, o senhor Polo refuta as lendas, como no caso do amianto, cujas origens animais, a partir da salamandra, são por ele recusadas. No entanto, não pode negar, sob pretexto de não tê-los verificado, alguns elementos que a geografia de seu tempo considera como bem reais, por exemplo, os homens com cauda ou com cabeça de cachorro (YERASIMOS, 1999, p. 31). Em outros casos, o viageiro faz uso de inúmeras expressões superlativas, como "o melhor produto" e "a mais bela cidade", os quais anulam comparações com outras espécies.

Entre tantos exemplos de adjetivação em último grau, Quelatu (Chieng-ming-Fu) brilha por ser a cidade das "três pontes de pedra, as mais formosas do mundo, com uma milha de comprido e ao menos oito passadas de largo" (POLO, 1997, p. 132). Até esse ponto, a narração não demonstra grandes sinais de deslumbramento, difundindo-se no contemplar objetivo, sem tanta admiração, pelos animais criados, as bebidas típicas, os climas, 
comportamentos, costumes, cultivos, festas, hábitos alimentares, religiosidade, ritos fúnebres e rituais cíclicos dos povos que vão sendo paulatinamente conhecidos.

Embora o veneziano pareça revelar contenção e ainda hoje seja tido por mentiroso, importa esclarecer que "uma parte das informações recebidas por Marco Polo é corroborada por fontes chinesas, mongóis ou persas. O mercador age como geógrafo, "seu livro chama-se A Descrição do Mundo, [descrevendo] inclusive os elementos legendários, os quais não se distinguem enquanto tais dos elementos reais" (YERASIMOS, 1999, p. 30).

Entre algumas situações dignas de registro, por deslumbrarem Polo, encontra-se a história de Aijarne, filha do rei Cadu da Grã Turquia. Parecendo remontar aos invencíveis gigantes dos livros apócrifos, à personagem ovidiana de Atalanta, à tradição popular e aos romances de cavalaria, tal "donzela era tão forte que não se encontrava ninguém que a pudesse vencer [...] era formosíssima e bem feita de todas as belezas" (POLO, 1997, p. 177178).

O olhar mágico, a exercer influências sobre as pessoas e as vidas envolvidas nessa mirada, reenvia àquela crença na petrificação frente ao belo. $\mathrm{O}$ olho, contudo, desvia-se dos sujeitos que são convertidos em objetos desejáveis e segue o rumo de objetos que acionam os mecanismos desse desejo. Não é de se estranhar que os fatos mais capazes de maravilhar o comerciante se relacionem a especiarias, peles, metais e pedras preciosos, ou seja, mercadorias e produtos que têm valor.

Nesse sentido, as velhas de uma província do Tibete, que mandam suas filhas concretizarem relações sexuais com os mercadores, vêm a ser simbolizadas como diversas da moral ocidental e do seu imaginário em vias de controle. Os símbolos instaurados no relato, entretanto, não se afastam da lógica metalista, a qual se mostrou propulsora das viagens européias do século XV:

E depois que o mercador fez sua vontade, convém dar-lhe alguma jóia para que ela possa mostrar que alguém com ela deitou-se. E aquela que tem mais jóias é sinal de que se deitou com muitos homens, e mais cedo se casa. E a cada uma, antes de casar, convém ter mais de vinte sinais no pescoço, para mostrar que muitos homens deitaram-se com ela; e a que mais os tiver por melhor será tida, e dizem que é mais graciosa que as outras. É gente malvada que adora ídolos, pois não tem por pecado fazer mal e roubar (POLO, 1997, p. 99).

O medievalista em reta final, nos caminhos do nascente capitalismo moderno, espantase com a província de Mie, onde um riquíssimo rei, chegada à hora da morte, "ditou que em cada ponta de sua sepultura fosse feita uma torre, uma de ouro e outra de prata [...] e digo-vos que é a coisa mais linda que se vê no mundo e também a de maior valor" (POLO, 1997, p. 109). Por outro caminho, no reino de Maabar, conhecido como Índia Maior, "mais nobre e rica província do mundo", o jovem Polo se assombra com "peixes que chamamos de ostras 
do mar, e destas tiram pérolas graúdas e miúdas de todos os feitios. E sabei que as pérolas encontradas nesse mar espalham-se por todo o mundo e, com isso, o rei tem grandes ganhos" (POLO, 1997, p. 148).

O valor da religiosidade igualmente transparece na narrativa, por intermédio da numerologia, prática popular no século XIII, que adapta certas interpretações do misticismo esotérico e dos neopitagóricos. Na Alta Idade Média, caracterizada pela visão simbólicoalegórica do universo, os ensinamentos dos discípulos de Pitágoras eram proporcionados pela migração do saber grego e oriental para o Ocidente. A concepção alegórica da natureza convivia com a concepção alegórica da arte, e a alegoria, como invento literário, ia se expandindo à sombra dos ideais cruzadistas, do declínio do papado, bem como da propagação das universidades e ordens de frades (FONSECA, 1991).

Como tal, a numerologia é uma modalidade alegórica de interpretação do mundo, com base na mística judaica, em variações empíricas da doutrina, que conduzem à Cabala. A interpretação cabalística parte das 22 letras do alfabeto hebraico, combinadas aos 32 caminhos da sabedoria, visando estabelecer orientações ao ser humano por meio de adições e decomposições numéricas desses algarismos. Dessa maneira, 22 (dois + dois) e 32 (três + dois) recaem na adição (quatro + cinco), levando ao número nove, que, por ser o último da série dos algarismos, anuncia, ao mesmo tempo, um fim e um recomeçar (SCHOLEM, 1999, p. 63-84).

Posteriormente adaptadas ao alfabeto romano, as relações simbólicas estendem-se a 26 letras, num eixo horizontal, as quais se combinam ao eixo vertical, compreendido pela progressão crescente dos numerais, de um a nove: a) primeiro conjunto - de A até I; b) de J a R; c) de $\mathrm{S}$ a Z . Cada um dos números combina-se com três letras, à exceção do nove, associado apenas ao I e ao R. Algumas interpretações d'As viagens são possibilitadas pela numerologia como se o narrador tivesse conhecimento de tal prática. O livro em análise oferece motivos para essa desconfiança, haja vista os freqüentes, e citados casos, de datas aí constantes que não conferem com outras informações, mais tarde, recolhidas.

Na província de Chamba, por exemplo, "no ano de 1285, conforme eu, Marco Polo, vi, aquele rei tinha trezentos e vinte e seis filhos entre meninos e meninas, e destes bem cento e cinqüenta em estado de portar armas" (POLO, 1997, p. 140). A combinação aditiva de 1285 resulta em sete, enquanto a de 326, em onze. Novamente decomposto (um + um), esse número produz dois e, por fim, 150 leva ao algarismo seis. O produto total dessas combinações (sete + dois + seis) corresponderia aos 15 anos de vida do jovem Polo no início 
da sua viagem. A idade pode ser decomposta no número seis — regente da sensibilidade e das pessoas de grande magnetismo.

Entre as muitas possibilidades de conexões que se abrem, com números contidos no texto d'As viagens, ressaltam-se as formas ternárias. Os reis tártaros são três, da mesma maneira que as Índias, as raças da Turcomênia, os reis magos e os membros da expedição de Marco até o território asiático. Os percursos relatados distam três jornadas, três milhas, três mil milhas etc. Assim também, Quinsai possui três mil banhos quentes, a 15 milhas de Jafu, onde o rei tem sob seu domínio "bem cento e quarenta grandes e ricas cidades. E sabei que a província de Manji tem bem umas mil e duzentas cidades [...] Em uma delas, por menos que haja, há mil guardas: numas dez mil, noutras vinte mil, noutras ainda trinta mil” (POLO, 1997, p. 128).

A operação numerológica encontrada no trajeto revive o magnetismo próprio ao número seis, ainda vinculado às fortunas inesperadas e à sorte nas questões financeiras. É o que esperam os mercadores da província de Maabar a encherem seus navios de cavalos. Levam-nos aos "cinco reis que são irmãos, e vendem cada um por cerca de quinhentos sêxtulos de ouro, pois valem mais de duzentos marcos de prata. E esse rei compra todo ano dois mil desses cavalos ou mais, e os irmãos outro tanto" (POLO, 1997, p. 150). As adições e decomposições desse "negócio da China" finalizam-se no cinco — da memória, destreza manual e vivacidade espiritual —, também a dirigir aquelas pessoas que procuram formas exóticas para ganhar dinheiro.

Além de se orientar pela busca da fortuna, Marco Polo tem o dom de ser escutado, reunindo considerável audiência para sua narrativa, ao longo dos séculos. Viaja por 24 anos, no período que vai de 1271 a 1295. A adição desses indicativos temporais (=16) é decomposta no sete, algarismo valorizado pelos numerólogos ocidentais, porque simboliza introspecção, intelectualidade, perfeição e a finalização dos ciclos. O mercador, três anos após regressar a Veneza, vem a ser preso em 1298 (20 = dois). Na veiculação dos relatos de suas viagens, são privilegiadas duas formas de discurso (direto e indireto), as quais se combinam a três pessoas da voz narrativa.

O resultado da equação de tais números leva a uma dezena que, decomposta, chega a um, o símbolo da criação. Criado pelo viajante, embora com a participação de outros, o "livro das maravilhas", descontados os 13 capítulos da parte introdutória, distribui-se em 170 seções. A desagregação e a correspondente adição dessa centena leva ao oito, numeral daqueles que sabem agir com diplomacia, dos corretores, políticos, cônsules e embaixadores. As mencionadas divisões do prólogo $(13=u m+$ três $)$ produzem quatro, que, somado ao seu 
antecedente, produz doze. Dissociada, tal dezena faz reaparecer o três, como visto, uma ocorrência constante na obra ditada pelo embaixador de Kublai Khan.

Marco Polo bem soube ouvir histórias para melhor contá-las e a sua narrativa faz eco ao provérbio retirado do versículo bíblico 15 (= seis) - "Quem tem ouvidos para ouvir, ouça" - , escrito pelo evangelista Mateus. O versículo se insere no capítulo 11 da Bíblia, associando-se ao número que simboliza a dissonância e o extravio. "Brasão do pecado", e conjugação do céu [cinco] com a terra $[\mathrm{seis}]^{4}$, a sua soma resulta em dois, algarismo das ambivalências e das emoções, mas que também conjuga o significado de lutas e oposições; dos embates entre os contrários, da dialética que pode renovar o antigo para dele nascerem outras sínteses.

Em uma ordem diversa da que anteriormente se apresentou, a soma de seis com dois provoca o regresso do oito, como retornado seria aquele veneziano à sua cidade-natal. Por fim, os 183 capítulos totais d' $O$ Milhão, ditados pelo comerciante enriquecido, e redigidos pelo escriba de empréstimo, ambos presos, confluem novamente ao doze. A decomposição desse algarismo resolve a curiosidade, crê-se que não acidental, sobre a insistência das instâncias narrativas em cidades, eventos e personagens agrupados em configurações ternárias. Além de perfazer uma simbologia erótica, o três vincula-se à ambição e às grandes conquistas (CHEVALIER; GHEERBRANT, 1999, p. 899-902).

Marco Polo não se configura propriamente como um conquistador, interessando-se mesmo pelas riquezas que a Ásia seria capaz de lhe oferecer; mais pelos produtos extraídos do solo asiático e pelas valiosas manufaturas a circularem num grande corredor de negócios do que por quinhões de terra ou benefícios de uma administração externa sobre aquele território. No entanto, não se deve elidir o fato de que o veneziano atua em favor da fé cristã, cujos meios de expressão, místicos ou racionalistas, impregnam o seu discurso e a narrativa da pessoa que ele escolhe para dar ciência de suas andanças pelo mundo oriental.

A ingenuidade do olhar dos relatores de viagens, conforme quer Correia, então se mostra invalidada. Além disso, o olho cobiçoso do mercador, a se maravilhar com tudo aquilo que lhe traga boa fortuna, minimiza aquele possível "olhar tripartido" em deslumbramento, horror e fantasia. Ressalvando-se algumas exceções, a tripartição não se confirma, pois Marco pode facilmente contornar embaraços e escapar de perigos. Maior parte

\footnotetext{
${ }^{4}$ Para Santo Agostinho, o onze é o "brasão do pecado"; sua ação perturbadora pode ser concebida como um desdobramento desequilibrador de um dos elementos do universo (o dez), vindo a determinar as desordens, as doenças e os erros. Essa inferência, bem como o simbolismo dos números dois, 11 e três, são devedores de: CHEVALIER; GHEERBRANT, 1999, p. 660-661, p. 899-902.
} 
das coisas e dos seres que encontra, ou são conhecidos do homem ocidental, ou ganham nomes que se adaptem às construções imaginárias do Ocidente.

$\mathrm{O}$ ato narratológico d'As viagens, como visto, compartilhado com um escritor de novelas de cavalaria, dá abrigo a várias expressões da cultura medieval, sejam elas eruditas ou populares, religiosas ou profanas. Talvez o sucesso receptivo, assim como a renovada leitura do texto, que persistem através dos anos, sejam tributários do seu caráter coloquial e do acolhimento a inúmeras narrativas da oralidade. Essas permanecem na voz do povo ou passam por labores literários; são entoadas em cânticos e canções, gravadas, filmadas ou representadas simbolicamente de distintas maneiras.

Veículos de cultura popular bastante em voga na Alta Idade Média, as associações numerológicas que o texto proporciona indicam outras formas de contaminação da escritura. Entre demais evidências, assinalam que, dos olhos do mercador, passando pelas falhas de sua alma memorialística, até chegar ao ouvido e à mão do escritor-fantasma, os manuscritos, depois, impressos, combinam-se por diferentes motivos. Podem vulgarizar o deslumbramento, banalizar o horror, até mesmo, fazer maravilhas da fantasia. Ainda são capazes de atravessar os mares, ouvir estrelas ou sereias, e levar o homem a longínquas milhas, desde os desertos a perder de vista até às pupilas bem abertas da Via-Láctea.

\section{Referências}

BENJAMIN, Walter. O narrador: considerações sobre a obra de Nikolai Leskov. In: Magia e técnica, arte e política: ensaios sobre literatura e história da cultura. São Paulo: Brasiliense, 1994. (Obras Escolhidas; v. 1). p. 197-221.

CAMÕES, Luís de. Os Lusíadas. Porto Alegre: Globo, 1982.

CHEVALIER, Jean; GHEERBRANT, Alain. Dicionário de símbolos: mitos, sonhos, costumes, gestos, formas, figuras, cores, números. 13. ed. Traduzido por Vera da Costa e Silva et al. Rio de Janeiro: José Olympio, 1999.

CORREIA, João David Pinto. Deslumbramento, horror e fantasia: o olhar ingênuo na Literatura de Viagens. In: CRISTÓVÃO, Fernando (Org.). O olhar do viajante: dos navegadores aos exploradores. Coimbra: Almedina, 2003. p. 11-33.

CRISTÓVÃO, Fernando (Org.). O olhar do viajante: dos navegadores aos exploradores. Coimbra: Almedina, 2003.

ECO, Umberto. Arte e beleza na estética medieval. Rio de Janeiro: Globo, 1993. 
FONSECA, Orlando. Na vertigem da alegoria: militância poética de Ferreira Gullar. 1991. Dissertação (Mestrado em Letras) - Pontifícia Universidade Católica do Rio Grande do Sul, Porto Alegre, 1991.

FRANCO JR, Hilário. Idade Média: nascimento do Ocidente. São Paulo Brasiliense, 1986.

KUBLAÏ KHAN ET NICOLO ET MATTEO POLO. Ilustração do livro de: POLO, Marco. Le devisement du monde. Texte intégral établi par A.-C. Moule et P. Pelliot. Version française de L. Hambis. Réimpr. avec une introduction et des notes de S. Yerasimos. Paris: La Découverte, 1998. 2 t. Figura extraída de: OXID.FR. 2004. Marco Polo (12541354). Disponível em: 〈http://www.marcopolo.mooldoo.com>. Acesso em: 05 jan. 2006. (Fig. 1).

POLO, Marco. As viagens. Traduzido por Ivone Castilho Benedetti. São Paulo: Martins Fontes, 1997. Tradução de Il libro di Marco Polo deto Il Milione.

POLO, Marco. O livro das maravilhas: a descrição do mundo. Traduzido por Elói Braga Júnior. Porto Alegre: L \& PM, 1999.

SCHOLEN, Gershom. O nome de Deus, a teoria da linguagem e outros estudos de cabala e mística: Judaica II. Tradução por Ruth Joanna Solon e J. Guinsburg. São Paulo: Perspectiva, 1999.

SCHOLEN, Gershom. A cabala e seu simbolismo. Traduzido por Hans Borger e J. Guinsburg. São Paulo: Perspectiva, 2004.

YERASIMOS, Stéphane. Sob os olhos do ocidente. In: POLO, Marco. O livro das maravilhas: a descrição do mundo. Traduzido por Elói Braga Júnior. Porto Alegre: L\&PM, 1999. p. 09-34. 